\title{
Review on the Medicinal Values of Ginger for Human and Animal Ailments
}

\section{Wondale Mekuriya and Berhanu Mekibib*}

School of Veterinary Medicine, Hawassa University, PO Box 05, Hawassa, Ethiopia

*Corresponding author: Berhanu Mekibib, School of Veterinary Medicine, Hawassa University, PO Box 05, Hawassa, Ethiopia, Tel: +251926308148; E-mail: berhanumm2002@gmail.com

Rec date: January 23, 2018; Acc date: February 20, 2018; Pub date: February 23, 2018

Copyright: (c) 2018 Mekuriya W, et al. This is an open-access article distributed under the terms of the Creative Commons Attribution License, which permits unrestricted use, distribution, and reproduction in any medium, provided the original author and source are credited.

\begin{abstract}
Traditional medicine has been utilized by the majority of the world population for thousands of years. Herbal medicines make up an important component of the traditional medicine and widely used as alternative or complimentary medications in most part of the world. Because of the growing problem of antibacterial resistance to commonly used antibiotics and the increasing prevalence of non-infectious diseases like diabetes and cancer, most researchers are switching their search for newer and alternative compounds to these potential plants. Ginger is one of the classic examples of herb used for unique therapeutic significance owing to its endowed nutraceutical compounds. The plant is extensively and widely studied for its medicinal value and botanical behavior. This review paper briefly summarizes for wider readers the presumed therapeutic potential of ginger both for human and animal diseases.
\end{abstract}

Keywords: Traditional Medicine; Ginger; Medicinal value; Human; Animal diseases

\section{Introduction}

Traditional medicine and medicinal plants have been utilized by the majority of the world population for thousands of years. Until the beginning of the 19th century, all medicines were traditional. Yet, in many developing countries, it is true that for the majority of rural population, traditional is the only primary or any other kind of health care available [1]. Traditional medicine is used throughout the world as it is dependent on locally available plants, which are easily accessible, and capitalizes on traditional wisdom-repository of knowledge, simple to use and affordable [2].

According to the World Health Organization (WHO), more than 3.5 billion people in the developing world rely on medicinal plants as components of their health care [3]. The vast majority of people (70-80\%) in Africa still consult Traditional Medical Practitioners (TMPs) for their healthcare $[3,4]$. For majority of them traditional medicine is the first, if not the only, health care system available for the treatment of numerous human and livestock diseases [1].

Moreover, the growing problem of antibacterial resistance to commonly used antibiotics has led to a search for newer and alternative compounds for the treatment of drug-resistant infections [5]. Secondary metabolites of medicinal plants yields an immeasurable wealth of chemical structures which has been and will continue to be a source of new drugs, directly in their native form and after optimization by synthetic medicinal chemistry.

Despite the great role of traditional medicine and medicinal plants in the primary health care, little work has so far been done in different part of the world and most of the information is still in the hands of the traditional healers [1]. The objective of this review is to compile the fragmented information available on the pharmacological activity and veterinary importance of ginger (Zingiber officinale).

\section{Brief description of ginger}

Ginger (Zingiber officinale) is usually found in grassland of humid regions as a weedy and herbaceous perennial herb which can reach about $2 \mathrm{~m}$ in height [6]. The plant can be named differently in different part of the world, for example Jeung or Sang Keong in Chinese, Adi or Adrack in Hindi, Jabe or Aliah in Indonesia, Gember in Dutch, Gingembre in French, Ingwar in German, Zenzero in Italian, Jengibre in Spanish [7].

Ginger belongs to the Family Zingiberaceae and has about 85 species of aromatic herbs [8]. The tuberous rhizome of ginger is a specialized segmented stem structure that grows horizontally just under the soil surface. The plant has narrowed lanceolate to linearlanceolate, $15-30 \mathrm{~cm}$ long leaves which die of each year and produces clusters of white and pink flower buds that bloom into yellow flowers [9].

Ginger is originated in South-East Asia and is the most common spice widely used all over the world [10]. Even though it is native to southern Asia, ginger is commonly cultivated in most tropical countries such as Jamaica, China, Nigeria and Haiti. In general it is believed to be commercially cultivated throughout the world [11].

\section{Active ingredients of ginger}

In general, more than 60 active constituents are known to be present in ginger, which have been broadly divided into volatile and nonvolatile compounds [10]. The root of the plant is rich in inulin, alantolucton, anti-spasm and essential oils [12]. The powdered rhizome contains $3-6 \%$ fatty oil, $9 \%$ protein, $60-70 \%$ carbohydrates, $3-8 \%$ crude fiber, about $8 \%$ ash, $9-12 \%$ water and $2-3 \%$ volatile oil [13].

Nutraceutical compounds usually claimed to have medicinal value includes gingerols, shogaol, gingerdiols, Ingenol, paradols and zingerone. Of which, gingerols are thought to be the most pharmacologically active components. Chemically gingerol and shogaols are composed of 6-, 8- and 10- structural analogs [11,14]. 


\section{Pharmacological activity}

Ginger has been used as Ayurvedic medicine from Vedic period and is called "mahaaushadhi", means the great medicine. In traditional medicine, it was used as a carminative or anti-flatulent. The Greek physician Galen used ginger as a purificant of body [15]. Recent study showed that it has antioxidant, anticancer, anti-inflammatory, antiapoptotic, anti-hyperglycemic, antihyperlipidemic and anti-emetic actions $[16,17]$.

Owing to its different active ingredients, ginger is considered as a safe medicinal plant with only few and insignificant adverse effects [9]. The major pharmacological activities of ginger are summarized as follows.

Lipolytic or Cholesterol-lowering properties: Ginger may reduce the rate of weight gain and hence adjust the Body Mass Index (BMI). It can improve body composition by decreasing body fat levels and increasing Soft Lean Mass (SLM). In addition, some enzymes such as Acetyl-coenzyme A, acyltransferase 1 and enoyl-CoA hydratase, which participate in the $\beta$-oxidation of fatty acids, have been increased by consumption of Ginger. Moreover, ginger extract prevents high-fat diet-induced obesity. The aqueous extract of $Z$. officinale called Roscoe might inhibit the intestinal absorption of dietary fat by inhibiting its hydrolysis. Therefore, ginger seems to improve body composition via its effects on liver enzymes, by reducing fat absorption, by increasing beta-oxidation of fats and energy expenditure [18].

Anti-inflammatory and analgesic actions: Ginger suppresses prostaglandin synthesis through inhibition of cyclooxygenase-1 and cyclooxygenase-2. It also suppresses leukotriene biosynthesis by inhibiting 5-lipoxygenase. This pharmacological property distinguishes ginger from NSAID (Non-Steroidal Anti-Inflammatory Drugs). Dual inhibitors of cyclooxygenase and 5-lipoxygenase may have a better therapeutic profile and have fewer side effects than NSAID [19]. For the human being, the consumption of fresh ginger demonstrated promising results for the decrease of arthritis-induced pain. However, more studies are necessary before concluding on a real effect of the consumption of ginger for the prevention and treatment of pain caused by chronic inflammatory disorders [14].

Ginger has a strong analgesic action which is many cases act by cyclooxygenase-1 (COX-1) inhibition. Gingerol and their derivatives, especially paradol, have been reported to be more potent anti-platelet and cyclo-oxygenase-1 (COX-1) inhibitors than aspirin [20].

As antioxidant: Antioxidants are the chemical substances that reduce or prevent oxidation stress and have the ability to counteract the damaging effects of free radicals in tissues. According to Chakraborty et al. gingerols are known to ease oxidative stress due to stimulation of superoxide dismutase, catalase, glutathione peroxidase and GSH activities [21]. They are believed to protect against cancer, arteriosclerosis, heart disease and several other diseases [11]. According to Kikuzaki and Nakatani, about 40 antioxidant compounds have been discovered in ginger [22]. Because of these chemicals, ginger has shown a protective role to toxicity and lethality against some agent like carbon-tetra chloride [23]. It can also protect DNA from lipopolysaccharide-induced oxidation damage in rats [14]. Ginger oil can act as a scavenger of oxygen radical and might be used as an antioxidant [19].

Antiemetic effects: Ginger is one of the herbs most commonly used to treat nausea and vomiting in pregnancy [24]. Although, the exact mechanism of action of ginger on nausea and vomiting remains uncertain, the components in ginger that are responsible for the antiemetic effect are thought to be the gingerols, shogaols, and galanolactone of ginger [19]. A 5\% solution of the essential oil of ginger in grape seed carrier oil, when applied nasocutaneously, can be administered safely for the effective prevention and therapeutic management of nausea in general anesthesia for patients at high risk for post-operative nausea and vomiting [14]. The possible mechanism of action of ginger is thought to be a gastric effect, i.e., it increase tone and peristalsis due to anti-cholinergic and anti-serotonin action [25]. However further studies have been recommended to determine the appropriate dose as antiemetic drug and its probable maternal and fetal complications [26].

Anti-microbial activity: Red ginger had strong antibacterial and to some extent antifungal properties because of gingerol, paradol, shogaols, zingerone [27,28]. Ingenol and shogaols, isolated from ginger rhizome, also demonstrated antiviral activity. In vitro studies had shown that active constituents of ginger inhibited multiplication of gastroenteric bacteria including Helicobacter pylori. The higher the concentration of the red ginger extracts, the more antimicrobial properties of the red ginger extracts, and the larger the diameter of the bacterial growth inhibition zones obtained [29]. Gingerol has been reported as active inhibitor of Mycobacterium avium and $M$. tuberculosis in vitro $[11,30]$. Ginger has shown antimicrobial activity against E. coli, Salmonella typhi and Bacillus subtilis and ethanolic extract of ginger showed widest zone of inhibition against Salmonella typhi $[28,31]$. According to Teimoory et al. the best antibacterial effect were obtained for the dried ginger at $42.6 \mathrm{mg}$ punch with the zone of 15.8 millimeter on Staphylococcus aureus and Listeria monocytogenes [6].

Although little is known about the mechanism of antimicrobial activities of ginger or its metabolites, the existing literatures indicated that the metabolites actually augment the activities of other antimicrobial compounds, thereby increasing their effectiveness. The active ingredients potentially cause increased disintegration of the bacterial cell walls, which could possibly interfere with the build-up of resistance of pathogens, thereby increasing the useful lifetime of antibiotics [11].

Anti-parasitic effect: Ginger is said to be anti-parasite plant in Iranian herbal medicine. A study conducted by Bahmani et al. showed a maximum anti-leech effect $(33.33 \pm 11.40 \mathrm{~min})$ of ginger that causes paralysis and death of the leeches in short time [32]. In this study, the lethal effect of methanolic extract of ginger against Limnatis nilotica (the common leech) was equal to levamisole and more than triclabendazole and methanolic extract of onion. So it can be concluded that ginger is a good natural medicine that can be used as anti-leech in order to decrease the leech pathological effects.

Gingerol and shogaols were also proved to be lethal to anisakis larvae at a minimal effective dose of 62.5 and $250 \mathrm{lg} / \mathrm{mL}$, respectively [33]. Therefore these compounds could have potential role to treat anisakiasis, a human parasitic infection of the gastrointestinal tract [11].

Gastro-protective effect: Ginger is the most proven herbal treatment for ulcers in human and horses, perhaps in other animals too. Ginger is a strong gastro-protectant that works by increasing mucin secretion, reducing the numbers of inflammatory cytokines, small proteins that signal to the immune system to begin an inflammatory response, in the stomach [34]. As a treatment for ulcers, when properly administered, ginger has shown to be as effective or better as cimetidine for treating 
ulcers [35]. Ginger does help repair existing damage to the stomach lining as well, but it has no direct effect on controlling inflammation, mucosal prostaglandin E2 (PGE2) content or reducing acidity in the stomach. According to Wang et al. the protective effect of ginger against gastric ulcers may be attributable to both gingerol and shogaol [34]. Moreover, some active components of ginger, including gingerol and shogaol, are reported to stimulate digestion, absorption, relieve constipation and flatulence by increasing muscular activity in the digestive tract [20].

Anti-tumor activity: Ginger and its constituents show a vital effect in the control of tumor development through up-regulation of tumor suppressor gene, induction of apoptosis and inactivation of VEGF pathways. Angiogenic factors such as VEGF (Vascular Endothelial Growth Factor) and FGF (fribroblast growth factor) play a significant role in the development and progression of tumor. Therefore, inhibition of VEGF and FGF is an important step in the prevention of tumor development/management [36]. The active ingredient 6gingerol has considerable role in the suppression of neoplastic transformation, hyperproliferation, and inflammatory processes that involve in various steps of carcinogenesis, angiogenesis and metastasis $[28,37]$. Several studies have shown that ginger has promising effect for liver cancer, breast cancer, prostate cancer and colorectal carcinomas through its diverse pharmaceutical mechanisms $[26,38]$.

Effects on cardiovascular system: Ginger is used to improve the flow of body fluids including blood. It stimulates blood circulation throughout the body by powerful stimulatory effect on the heart muscle and by diluting blood. A Japanese study showed that active constituents in ginger reduced the blood pressure and decreased cardiac workload [13]. Ginger has been shown to inhibit platelet aggregation and to decrease platelet thromboxane production in vitro $[14,30]$. Ginger reduced the formation of pro inflammatory prostaglandins and thromboxane thus lowering the clotting ability of the blood. Ginger can also prevent the increase in cholesterol levels following intake of cholesterol-rich diet [13].

Anti-diabetic activity of ginger: Ginger and its constituents showed pivotal role in the control of diabetes and the associated complications via its anti hyperglycemic effect. Studies on animal models showed that ginger extract and ginger juice have significant blood glucose lowering effect or hypoglycemic activity both in diabetic and non-diabetic groups [39,40].

Although the exact mechanism of action of ginger in diabetes control is not still fully understood inhibition of oxidative stress and anti- inflammatory process could be another possible mechanism [28]. Ginger shows antagonistic activity against serotonin receptors. Moreover, it inhibits the activity of intestinal glucosidase and amylase, resulting in the reduction of glucose absorption [18]. Animal based studies further indicated the ability of 6-GN to increase plasma insulin levels and to improve diabetes-induced myocardial diastolic dysfunction and enhance the relaxation and the $\mathrm{Ca} 2+$ transient decay rate $[11,41]$.

Renoprotective and kidney function: Gingerol fraction from Zingiber officinale prevents gentamicin-induced nephrotoxicity. It improves kidney functions, reduces lipid peroxidation, and enhancing the levels of reduced glutathione, superoxide dismutase and catalase activities [11]. In addition, Ginger extract diminishes chronic fructose consumption-induced kidney injury by suppression of renal over expression of pro-inflammatory cytokines in rats [18]. The nephronprotection of ginger is mediated by preventing the Doxorubicin induced decline of renal antioxidant status, and also by increasing the activity of Glutathione -S- transferse [23].

Neuro-protective effect: Ginger plays an important role in the improvement of symptoms in patients who suffer from Alzheimer and other neurological diseases. The neuro-protective effect is partly attributable to an antagonistic action of ginger root extracts on monosodium glutamate effect, so the monoamines content was increased. From these results, we can say that the ginger extract has a neuro-protective role against monosodium glutamate toxicity effect [23].

Experimental trials on animal models further indicate that gingerol and other constituents of ginger were found to be effective in alleviating neuropathic pain [42], to block prion peptide-mediated neurotoxicity and to be strong antidepressants [43].

\section{Veterinary importance of ginger}

Cattle: Ginger roots contains ingredients like Aryl alkanes that give ginger pungent taste that enhancing the appetite of animal and improve the nutrients palatability which finally caused increased feed intake. Ginger may also be attributed to enhanced synthesis of bile acids in the liver and their excretion in bile, which beneficially increase the digestion and absorption of lipids. It also helps to increase the absorption of essential nutrients and to increase stability of feed and beneficially influence the gastrointestinal ecosystem through inhibition of pathogenic micro-organisms growth [44].

Methanolic extract of ginger showed a maximum anti-leech effect $(33.33 \pm 11.40 \mathrm{~min})$ which is reflected by causing paralysis and death of the leeches in short time. Leech infestation may cause serious complications like lethal dyspnoea, haemoptysis or haematemesis and other sever complications if left untreated [32].

Equine: Ginger extract has promising effect on recovery time for horses competing in endurance, jumping or racing events. The ginger extract did not affect other physiological responses to exercise, such as heart rate, blood pressure, run-time to fatigue, plasma lactate concentration, core temperature or rectal temperature. However, further analysis of the compounds present in ginger extract is needed to determine whether those compounds would be picked up by drug tests often done at competition [45].

In the current veterinary practice, many professionals and horse owners are turning to herbal preparations to treat ulcer cases where the horse does not respond or responds adversely to more commonly used medications, such as omeprazole or ranitidine, or when trying to prevent future cases of ulcers in ulcer-prone horses. Among the herbal preparations, ginger is the most proven herbal treatment for ulcers in horses [46].

Poultry: The European Union banned the use of antibiotic feed additives and nutritionists are trying to find alternatives, one of the best options is herbs. Powdered rhizome of ginger is one such potential herb with a wide range of medicinal effects. In broilers and layers, this plant has been used in different forms, doses and durations [47]. Whilst reports regarding the efficacy of ginger in poultry diets vary, there are indications that feeding this plant material can promote growth performance and weight gain in broilers, egg laying characteristics in hens and may be involved in enhancing gut function and anti-oxidation in poultry. Most of the researchers postulated that due to the effect of this natural product, the digestive tract would have been emptied earlier and feed consumption will have been promoted 
[48]. A preliminary result of Sutardi et al. also suggested a couple of promising antibacterial properties of wild ginger from Indonesia, and probably could be used in management of chronic respiratory disease in chickens which is caused Mycoplasma gallisepticum [49].

Fish: Extensive use of antibiotics in aquaculture leads to the emergence of antibiotic-resistant bacteria and generation of toxicants. To alleviate these problems, increasing attention is being given to the use of natural alternative feed additives such as ginger for diseasecontrol strategies in aquaculture. Ginger enhances resistance to infectious disease by increasing non-specific and specific immune mechanisms thereby helps to reduce the losses caused by diseases in aquaculture [50]. Moreover, when ginger was used at a dose of $0.5 \mathrm{~g} / \mathrm{kg}$ feed, mortality was reduced to zero compared to the control group, at the same time an enhancement of growth rate, feed conversion and protein efficiency being observed [51].

The application of ginger in aquaculture is suggested by some researchers an innovative approach to enhance health of fish and to prevent diseases. It provides protection against invading microorganisms, including bacteria such as E. coli and Staphylococcus aureus (a common cause of skin infections) and fungi, including Candida albicans [50]. Putrefaction/rancidity on fish impart offensive odor on fish which affect its consumption and ultimately, its marketability. Ginger is a strong antioxidant substance and may either mitigate or prevent generation of free radicals [52].

\section{Conclusion and Recommendations}

Ginger is one of the well known medicinal herbs that are used both by traditional healers and in some modern treatment modalities. Research outputs suggest that the nutraceutical compounds of ginger can have values as a complementary treatment for several forms of cancer and ailments of both human and animals. Moreover, several studies are underway to identify the most valuable active ingredients responsible for the presumed therapeutic effects and to formulate commercially and therapeutically feasible medicines from these ingredients. Awaiting the different stages of clinical trials and authentications of formulated drugs from the plant, the existing preclinical information is sufficient to recommend ginger and its extract as complementary treatment option for some diseases of human and animals particularly in resource poor communities.

\section{Conflict of Interests}

We don't have conflict of interest and the article is compiled and prepared by both authors.

\section{Acknowledgements}

We would like to thank individuals who voluntarily provided softcopy or hardcopy of their personal or group work.

\section{References}

1. Seifu T (2004) Ethnobotanical and Ethnopharmaceutical studies on medicinal plants of Chifra district, Afar Region, North Eastern Ethiopia. Msc Thesis. Addis Ababa University, Addis Ababa, Ethiopia.

2. Bekele G, Reddy PR (2015) Ethnobotanical Study of Medicinal Plants Used to Treat Human Ailments by Guji Oromo Tribes in Abaya District, Borana, Oromia, Ethiopia. Universal J Plant Sci 3: 1-8.
3. Cunningham AB (1993) African Medicinal Plants: Setting Priorities at the Interface between Conservation and Primary Healthcare People and Plants Working Paper 1. Paris.

4. Chekole G (2011) An ethnobotanical study of plants used in traditional medicine and as wild foods in and around Taragedam and Amba Remnant Forests. Msc thesis, Plant Biology and Biodiversity Management, Addis Ababa, Ethiopia.

5. Sibanda T, Okoh AI (2008) In vitro evaluation of the interactions between acetone extracts of Garcinia kola seeds and some antibiotics. Afr J Biotech 7: 1627-1678.

6. Teimoory H, Azizi M, Najafi MF, Behzadi A, Rezaei M (2013) Antibacterial activity of Myrtus communis L. and Zingiber officinale extracts against some Gram positive pathogens. Res Opin Anim Vet Sci 3: 478-481.

7. Ravindran P, Babu K, Shiva K (2005) Botany and Crop Improvement of Ginger. In: Ravindran P and Babu K (Eds.) (2005) Ginger: The Genus Zingiber. Florida, USA: CRC Press. pp 15-85.

8. El-Sayed NM (2015) Anti-Parasitic Activity of Zingiber officinale (Ginger): Brief Review. Aperito J Bacteriol Virol Parasitol 2: 1-7.

9. Toader OR (2014) Study of the effects of Zingiber officinale (ginger) on spermatogenesis in mice. Annales of West University of Timişoara, Series of Biology 17: 145-152.

10. Ahmed B, Rehman MU, Amin I, Arif A, Rasool S, et al. (2015) A review on pharmacological properties of Zingerone (4-(4-Hydroxy-3methoxyphenyl)-2-butanone). Scientific World J. Article ID 816364, 6 pages.

11. Semwal RB, Semwal DK, Combrinck S, Viljoen AM (2015) Gingerols and shogaols: Important nutraceutical principles from ginger. Phytochemistry 117: 554-568.

12. Al-Amin ZM, Thomson M, Al-Qattan KK, Peltonen-Shalaby R, Ali M (2006) Anti-diabetic and hypolipidaemic properties of ginger (Zingiber officinale) in streptozotocin-induced diabetic rats. Br J Nutr 96: 660-666.

13. Zadeh JB, Kor NM (2014) Physiological and pharmaceutical effects of Ginger (Zingiber officinale Roscoe) as a valuable medicinal plant. Eur J Exp Biol 4: 87-90.

14. Tchombé NL, Louajri A, Benajiba MH (2012) Therapeutic effects of ginger (Zingiber officinale). ISESCO J Sci Technol 8: 64-69.

15. Polasa K (2003) Ginger and its role in xenobiotic metabolism. ICMR Bulletin 33: 58-63.

16. Rehman R, Akram M, Akhtar N, Jabeen Q, Saeed T, et al. (2010) Zingiber officinale Roscoe (pharmacological activity). J Med Plants Res 5: 344-348.

17. Kumar S, Saxena K, Singh UN, Saxena R (2013) Anti-inflammatory action of ginger: A critical review in anemia of inflammation and its future aspects. Int J Herb Med 1: 16-20.

18. Aryaeian N, Tavakkoli H (2015) Ginger and its effects on inflammatory diseases. Adv Food Technol Nutr Sci 3: 97-101.

19. Yadav S, Sharma PK, Alam MA (2016) Ginger medicinal uses and benefits. Eur J Pharm Med Res 3: 127-135.

20. Ghosh AK, Banerjee S, Mullick HI, Banerjee J (2011) Zingiber Officinale: A natural gold. Int J Pharm Bio Sci 2: 283-294.

21. Chakraborty D, Mukherjee A, Sikdar S, Paul A, Ghosh S, et al. (2012) [6]Gingerol isolated from ginger attenuates sodium arsenite induced oxidative stress and plays a corrective role in improving insulin signaling in mice. Toxicol Lett 210: 34-43.

22. Kikuzaki H, Nakatani N (1996) Cyclic diarylheptanoids from rhizomes of Zingiber offcinale. Phytochemistry 43: 273-277.

23. Singh SK, Patel JR, Bachle D (2014) A review on Zingiber officinale: A natural gift. Int J Pharm Bio Sci 5: 508-525.

24. Allaire AD, Moos MK, Wells SR (2000) Complementary and alternative medicine in pregnancy: A survey of North Carolina certified nursemidwives. Obstet Gynecol 95: 19-23.

25. Bryer E (2005) A literature review of the effectiveness of ginger inalleviating mild-to-moderate nausea and vomiting of pregnancy. J Midwifery Womens Health 50: e1-e3. 
26. Pour HA, Norouzzade R, Heidari MR, Ogut S, Yaman H, et al. (2014) Therapeutic properties of Zingiber officinale Roscoe: A Review. European J Med Plants 4: 1431-1446.

27. Malu SP, Obochi GO, Tawo EN, Nyong BE (2008) Antibacterial activity and Medicinal properties of Ginger (Zingiber officinale). Glob J Pure Appl Sci 15: 365-368.

28. Rahmani AH, Al shabrmi FM, Aly SM (2014) Active ingredients of ginger as potential candidates in the prevention and treatment of diseases via modulation of biological activities. Int J Physiol Pathophysiol Pharmacol 6: 125-136.

29. Poeloengan M (2011) The effect of red ginger (Zingiber officinale Roscoe) extract on the growth of mastitis causing bacterial isolates. Afr J Microbiol Res 5: 382-389.

30. Mishra RK, Kumar A, Kumar A (2012) Pharmacological Activity of Zingiber officinale. Int J Pharm Chem Sci 1: 1422-1427.

31. Azu N, Onyeagba R (2007) Antimicrobial properties of extracts of Allium cepa (Onions) and Zingiber officinale (Ginger) on Escherichia coli, Salmonella typhi and Bacillus subtilis. Internet J Trop Med 3: 1-10.

32. Bahmani M, Vakili-Saatloo N, Gholami-Ahangaran M, Karamati SA, Banihabib E, et al. (2013) A comparison study on the anti-leech effects of onion (Allium cepa L) and ginger (Zingiber officinale) with levamisole and triclabendazole. J Herbmed Pharmacol 2: 1-3.

33. Goto C, Kasuya S, Koga K, Ohtoma H, Kagei N (1990) Lethal efficacy of extract from Zingiber officinale (traditional Chinese medicine) or [6]shogaol and [6]- gingerol in Anisakis larvae in vitro. Parasitol Res 76: 653-656.

34. Wang Z, Hasegawa J, Wang X, Matsuda A, Tokuda T, et al. (2011) Protective effects of ginger against aspirin-induced gastric ulcers in rats. Yonago Acta Med 54: 11-19.

35. Kumar SP, Pal KI (2011) Development and evaluation of a gastroretentive delivery system for improved antiulcer activity of ginger extract. J Drug Target 19: 741-751.

36. Kim EC, Min JK, Kim TY, Lee SJ, Yang HO, et al. (2005) [6]-Gingerol, a pungent ingredient of ginger, inhibits angiogenesis in vitro and in vivo. Biochem Biophys Res Commun 335: 300-308.

37. Lee HS, Seo EY, Kang NE, Kim WK (2008) [6]-Gingerol inhibits metastasis of MDA-MB-231 human breast cancer cells. J Nutr Biochem 19: 313-319.

38. Karna P, Chagani S, Gundala SR, Rida PC, Asif G, et al. (2012) Benefits of whole ginger extract in prostate cancer. Br J Nutr 107: 473-484.

39. Sharma M, Shukla S (1977) Hypoglycaemic effect of ginger. J Res Ind Yoga Homeop 12: 127-130.

40. Ahmed RS, Sharma SB (1997) Biological studies on combined effects of garlic (Allium sativum Linn) and ginger (Zingiber officinale Roscoe) in albino rats. J Exp Biol 35: 841-843
41. Namekata I, Hamaguchi S, Wakasugi Y, Ohhara M, Hirota Y, et al. (2013) Ellagic acid and gingerol, activators of the sarco-endoplasmic reticulum Ca2+-ATPase, ameliorate diabetes mellitus-induced diastolic dysfunction in isolated murine ventricular myocardial. Eur J Pharmacol 706: 48-55.

42. Gauthier ML, Beaudry F, Vachon P (2013) Intrathecal [6]-gingerol administration alleviates peripherally induced neuropathic pain in male Sprague-Dawley rats. Phytother Res 27: 1251-1254.

43. Ittiyavirah SP, Paul M (2013) In silico docking analysis of constituents of Zingiber officinale as antidepressant. J Pharmacogn Phytother 5: 101-105.

44. Shams Al-dain ZQ, Jarjeis EA (2015) Vital impact of using ginger roots powder as feed additive to the rations of local Friesian dairy cows and its effect on production \& economic efficiency of milk and physiological of blood. Kufa J Vet Sci 6: 155-165.

45. Liburt NR, McKeever KH, Streltsova JM, Franke WC, Gordon ME, et al. (2010) Effects of ginger and cranberry extracts on the physiological response to exercise and markers of inflammation in horses. Comp Exerc Physiol 6: 157-169.

46. Feed for thought (2017) Herbal preparations. Available from: http:// www.cavalor.com/library/news/1233/documents/ Cavalor_FeedForThought_12_Herbal\%20Preparations_Why\%20are \%20they\%20effective\%20in\%20treating\%20ulcers.pdf Accessed date Nov 26, 2017.

47. Salih YG, Gurbuz Y (2015) Sumac (Rhus Coriaria L.) and Ginger (Zingiber officinale) as feed additive in poultry nutrition. KSU J Nat Sci 18: 44-46.

48. Khan RU, Naz S, Nikousefat Z, Tufarelli V, Javdani M, et al. (2012) Potential applications of ginger (Zingiber officinale) in poultry diets. World's Poult Sci J 68: 245-252.

49. Sutardi LN, Wientarsih I, Handharyani E, Andriani M, Setiyono A (2015) Indonesian wild ginger (Zingiber $s p$ ) extract: Antibacterial activity against Mycoplasma gallisepticum. IOSR J Pharmacy 5: 59-64.

50. Shakya SR (2015) Medicinal uses of ginger (Zingiber officinale Roscoe) improves growth and enhances immunity in aquaculture. Int J Chem Stud 3: 83-87.

51. Gabor EF, Şara A, Barbu A (2010) The Effects of Some Phyto-additives on Growth, Health and Meat Quality on Different Species of Fish. Anim Sci Biotechnol 43: 61-65.

52. Kumolu-Johnson CA, Ndimele PE (2011) Ant-oxidative and anti-fungal effects of fresh ginger (Zingeber officinale) treatment on the shelf life of hot smoked cat fish (Clarious gariepinus). Asian Journal of Biological Sciences 4: 532-539. 